\title{
Buspirone pharmacokinetics in patients with cirrhosis
}

\author{
K. DALHOFF ${ }^{1}$, H. E. POULSEN ${ }^{1,2}$, P. GARRED $^{1}$, M. PLACCHI ${ }^{3}$, R. E. GAMMANS ${ }^{4}$, R. F. MAYOL ${ }^{4} \&$ \\ M. PFEFFER ${ }^{5}$ \\ ${ }^{1}$ Department of Medicine A, Division of Hepatology, Rigshospitalet, Copenhagen, Denmark, ${ }^{2}$ Department of \\ Pharmacology, University of Copenhagen, Copenhagen, Denmark, Bristol-Myers Pharmaceutical and \\ Development Division, ${ }^{3}$ Bruxelles, Belgium, ${ }^{4}$ Evansville, Indiana, ${ }^{5}$ Syracuse, New York, USA
}

The pharmacokinetics of a single oral dose of buspirone $(20 \mathrm{mg})$ were determined in 12 patients with cirrhosis and 12 normal subjects. The mean AUC of buspirone was $55 \pm 38$ s.d. $\mathrm{ng} \mathrm{ml}^{-1} \mathrm{~h}$ in cirrhotics and $3.5 \pm 2.4$ s.d. $\mathrm{ng} \mathrm{ml}^{-1} \mathrm{~h}$ in normals. The time until maximum concentration $\left(t_{\max }\right)$ attained was similar in the two groups $(0.6 v s 0.7 \mathrm{~h})$, but mean maximum concentration $C_{\max }$ was higher in patients $\left(18.8 \pm 16.3 \mathrm{~s} . \mathrm{d} . \mathrm{ng} \mathrm{m}^{-1}\right)$ than in normals $\left(1.2 \pm 0.8 \mathrm{~s}\right.$.d. $\left.\mathrm{ng} \mathrm{ml}^{-1}\right)$. Mean elimination half-life of buspirone was greater in cirrhotics, but this difference was marginally significant statistically (cirrhotics, $6.1 \pm 3.5$ s.d. h; normals $3.2 \pm 1.5$ s.d. h, $P=0.05$ ). Eight of 12 patients and seven of 12 normal subjects had a second peak in the plasma concentrations of buspirone. In patients this occurred at $10.8 \pm 7.4 \mathrm{~s} . \mathrm{d}$. $\mathrm{h}$ after the dose, and its mean concentration was $3.1 \pm 6.6 \mathrm{ng}$ $\mathrm{ml}^{-1}$. In normal subjects the second peak occurred at $4.3 \pm 2.1 \mathrm{~h}$ after the dose and its mean concentration was $0.5 \pm 0.3 \mathrm{ng} \mathrm{ml}^{-1}$. On the kinetic evidence buspirone should be used with caution in liver disease.

Keywords buspirone cirrhosis pharmacokinetics

\section{Introduction}

Buspirone hydrochloride, 8-(4-4-(2-pyrimidinyl))1-piperazinyl(butyl)-8-azaspiro(4.5)decame-7.9dione hydrochloride, is a new drug with anxiolytic activity (Temple et al., 1982; Riblet et al., 1982; Garattini et al., 1982). On the basis of radiolabelled studies in normals (Mayol et al., 1985), buspirone is absorbed completely after an oral dose, undergoes extensive presystemic metabolism, has a large apparent volume of distribution and a high plasma clearance. The two major metabolites (a 5-hydroxy derivative and a glucuronide) are eliminated in urine and faeces. The plasma half-life of the parent compound is about $2 \mathrm{~h}$ in normals, but the half-lives of the metabolites are over $8 \mathrm{~h}$.

As a consequence of this, liver disease could change the metabolism of buspirone, to a clinically important degree, requiring changes in dose or dose intervals. The purpose of the present study was to investigate the kinetics of buspirone elimination in patients with cirrhosis.

\section{Methods}

Twelve male patients entered the study, eleven with biopsy-proven cirrhosis, eleven alcoholinduced and one xylene-induced (patient 445). Twelve healthy males without evidence of liver disease also were studied. The patients were admitted just prior to the study, none was encephalopathic and none had gastro-intestinal bleeding. Three had mild ascites. The patients were about twice as old as the controls, but there

Correspondence: Dr H. E. Poulsen, Department of Medicine A, Division of Hepatology A2152, Rigshospitalet, Copenhagen, Denmark 
was no significant difference in body weight. Most patients were already receiving diuretics and Vitamin $\mathrm{K}$, and six patients (nos. 432, 438, $445,447,449$ and 451 ) received additional medication (see Table 1).

Galactose elimination capacity (GEC) (Tygstrup, 1966) and antipyrine clearance (Døssing et al., 1982) were measured prior to administration of buspirone. An ECG was recorded and prothrombin index $(0.85-1.15)$, albumin (532-813 $\mu \mathrm{mol} \mathrm{l}^{-1}$ ), alanine-aminotransferase $\left(10-40 \mathrm{u} \mathrm{l}^{-1}\right)$, and alkaline phosphatases (50-275 $\mathrm{u}^{-1}$ ) were measured by routine laboratory methods before and $48 \mathrm{~h}$ after administration of buspirone (normal values given in parenthesis). Data are given in Table 1.

The study was approved by the local ethics committee and written informed consent was obtained. Patients and subjects were asked to report side effects.

\section{Protocol}

After an overnight fast each person took a single oral $20 \mathrm{mg}$ dose of buspirone with $120 \mathrm{ml}$ of water and continued to fast for $3 \mathrm{~h}$. Blood samples were obtained before drug administration and $0.25,0.5,0.75,1,2,3,4,6,8,11,15,24$ and $36 \mathrm{~h}$ post dose through a cannula in a peripheral vein. Plasma was separated and stored at $-20^{\circ} \mathrm{C}$ until analysis.

After hexane extraction, buspirone plasma concentrations were measured by a specific radioimmunoassay (Mayol et al., 1981). Antibody

Table 1 Clinical and laboratory data in patients with liver cirrhosis and in healthy controls

\begin{tabular}{|c|c|c|c|c|c|c|c|c|c|}
\hline Subject & $\begin{array}{c}\text { Weight } \\
(\boldsymbol{k g})\end{array}$ & $\begin{array}{c}\text { Age } \\
\text { (years) }\end{array}$ & $\underset{\text { (ratio) }}{P P}$ & $\underset{\left(\mu \mathrm{mol} l^{-1}\right)}{\operatorname{Albumin}}$ & $\begin{array}{c}A L A T \\
\left(u l^{-1}\right)\end{array}$ & $\begin{array}{c}A l k P h \\
\left(u l^{-1}\right)\end{array}$ & $G E^{\mathbf{a}}$ & $A P-C L^{\mathrm{b}}$ & $\begin{array}{l}\text { Other } \\
\text { drugs }\end{array}$ \\
\hline \multicolumn{10}{|l|}{ Patient } \\
\hline 432 & 68 & 39 & 0.67 & 434 & 50 & 267 & 13.1 & 0.76 & 3 \\
\hline 438 & 81 & 28 & 0.38 & 287 & 25 & 398 & 17.0 & 0.61 & 1 \\
\hline 437 & 87 & 50 & 1.20 & 538 & 16 & 344 & 24.1 & 0.60 & \\
\hline 439 & 74 & 61 & 0.65 & 331 & 20 & 478 & 21.4 & 0.52 & \\
\hline 449 & 70 & 42 & 0.89 & 667 & 9 & 236 & 22.3 & 0.49 & 1 \\
\hline 452 & 78 & 54 & 0.78 & 629 & 40 & 418 & 20.5 & 0.41 & \\
\hline 451 & 96 & 41 & 1.62 & 684 & 95 & 316 & 30.0 & 0.39 & 1 \\
\hline 431 & 115 & 45 & 1.05 & 719 & 58 & 315 & 30.4 & 0.30 & \\
\hline 447 & 86 & 48 & 0.71 & 560 & 40 & 384 & 26.4 & 0.28 & 1 \\
\hline 450 & 62 & 40 & 0.42 & 357 & 16 & 561 & 24.5 & 0.27 & \\
\hline 445 & 65 & 45 & 0.59 & 553 & 14 & 366 & 20.8 & 0.24 & 2 \\
\hline 446 & 79 & 50 & 0.66 & 602 & 39 & 399 & 23.5 & 0.17 & \\
\hline Mean & 80 & 45 & 0.80 & 530 & 35 & 374 & 22.8 & 0.42 & \\
\hline s.d. & 15 & 8 & 0.35 & 145 & 25 & 89 & 4.9 & 0.18 & \\
\hline \multicolumn{10}{|l|}{ Control } \\
\hline 433 & 72 & 23 & 0.84 & 670 & 16 & 112 & 32.1 & 1.72 & \\
\hline 443 & 70 & 20 & 1.15 & 770 & 16 & 225 & 46.3 & 1.70 & \\
\hline 444 & 70 & 21 & 0.81 & 598 & 17 & 188 & 38.1 & 1.63 & \\
\hline 434 & 84 & 28 & 1.52 & 599 & 28 & 340 & 31.8 & 1.42 & \\
\hline 436 & 62 & 26 & 0.88 & 639 & 15 & 206 & 36.5 & 1.15 & \\
\hline 441 & 72 & 25 & 0.86 & 658 & 34 & 280 & 29.9 & 1.00 & \\
\hline 440 & 65 & 27 & 0.97 & 726 & 20 & 245 & 38.9 & 0.92 & \\
\hline 435 & 78 & 37 & 1.09 & 645 & 16 & 158 & 30.4 & 0.87 & \\
\hline 442 & 73 & 24 & 0.60 & 698 & 13 & 214 & 27.8 & 0.74 & \\
\hline 454 & 70 & 27 & 1.07 & 779 & 24 & 195 & 34.4 & 0.66 & \\
\hline 448 & 83 & 36 & 1.11 & 688 & 19 & 124 & 29.2 & 0.55 & \\
\hline 453 & 75 & 27 & 0.97 & 692 & 13 & 153 & 35.7 & 0.43 & \\
\hline Mean & 73 & 27 & 0.99 & 680 & 19 & 203 & 34.3 & 1.07 & \\
\hline s.d. & 6 & 5 & 0.23 & 58 & 6 & 65 & 5.2 & 0.46 & \\
\hline
\end{tabular}

$\mathrm{PP}=$ prothrombin index ( $\%$ of control value); $\mathbf{A L A T}=$ alanine-aminotransferase; $\mathrm{Alk} \mathrm{Ph}=$ alkaline phosphatase; GE galactose elimination; $\mathrm{AP}-\mathrm{CL}=$ antipyrine clearance.

$10^{-3} \mathrm{mg} \mathrm{min}^{-1} \mathrm{~kg}^{-1}$ body weight.

${ }^{b} \mathrm{ml} \mathrm{min}^{-1} \mathbf{k g}^{-1}$ body weight.

1 diazepam; 2 cimetidine; diazepam; 3 diazepam, phenobarbitone, disulfiram. 
for the assay was produced in rabbits by injection of buspirone coupled to bovine serum albumin via a hemisuccinamide of the 5-amino pyramidinyl derivative. The lower limit of measurement was $0.06 \mathrm{ng} \mathrm{ml}^{-1}$. The coefficient of variation for five repeated measurements was less than $9 \%$ in the concentration range $0.06-1.25 \mathrm{ng} \mathrm{ml}^{-1}$ plasma and somewhat higher for concentrations up to $10 \mathrm{ng} \mathrm{ml}^{-1}$ plasma.

\section{Calculations}

The elimination half-life $\left(t_{1 / 2}\right)$ was estimated from the terminal part of the plasma drug concentration-time curve using regression analysis. In those cases where a second peak (defined as a concentration value higher than the previous value) was apparent, the elimination $t_{1 / 2}$ estimation was based upon the data points after the second peak. The area under the plasma concentration-time curve from 0 to the last time point $t \operatorname{AUC}(0, t)$ was calculated using the linear trapezoidal rule. AUC from $t$ to infinity was extrapolated as $C(t) / k$, where $k$ is the estimated elimination rate constant. The extrapolated area was $20 \%$ of total AUC in controls and $2 \%$ of total AUC in cirrhotics; the numeric values of the extrapolated areas were similar.

Differences between controls and cirrhotics were tested with the two-tail Student's $t$-test, $P$ values less than 0.05 were considered to be significant statistically.

\section{Results}

Individual and mean pharmacokinetic data are given in Table 2.

Table 2 Kinetic parameters of patients with liver cirrhosis and healthy controls after a single oral dose of $20 \mathrm{mg}$ buspirone

\begin{tabular}{|c|c|c|c|c|c|c|}
\hline Subject & $\begin{array}{c}\mathrm{C}_{\max } \\
\left(n g \operatorname{ml}^{-1}\right)\end{array}$ & $\begin{array}{c}\mathrm{t}_{\max } \\
(h)\end{array}$ & $\underset{\left(n g m l^{-1} h\right)}{A U C}$ & $\begin{array}{l}\mathrm{t}_{1 / 2} \\
(h)\end{array}$ & $\begin{array}{r}\quad \text { Secc } \\
\text { Time after } \\
\text { dosing }(h)\end{array}$ & $\begin{array}{l}\text { nd peak } \\
\text { Concentration } \\
\left(\text { ng } \mathrm{ml}^{-1}\right)\end{array}$ \\
\hline \multicolumn{7}{|l|}{ Patient } \\
\hline 432 & 1.11 & 0.5 & 6.0 & 4.6 & 4 & $\begin{array}{r}0.68 \\
0.50\end{array}$ \\
\hline 438 & 23.84 & 0.6 & 68.3 & 6.0 & 4 & 9.58 \\
\hline 437 & 51.34 & 0.4 & 84.3 & 8.6 & 18 & 0.86 \\
\hline 439 & 33.07 & 0.5 & 102.5 & 5.4 & - & - \\
\hline 449 & 3.88 & 2.0 & 17.9 & 16.3 & 24 & 0.10 \\
\hline 452 & 1.90 & 0.5 & 46.3 & 6.1 & 4 & 7.44 \\
\hline 451 & 40.54 & 0.5 & 88.5 & 3.9 & - & - \\
\hline 431 & 3.89 & 0.5 & 9.7 & 4.3 & 14 & 0.51 \\
\hline 447 & 21.01 & 0.3 & 35.4 & 5.9 & 8 & 1.49 \\
\hline 450 & 14.73 & 0.5 & 69.9 & 4.3 & - & - \\
\hline 445 & 20.49 & 0.3 & 115.4 & 3.5 & 10 & 4.20 \\
\hline 446 & 10.02 & 0.25 & 16.2 & 3.9 & - & - \\
\hline Mean & $18.82 *$ & 0.6 & $54.7^{*}$ & $6.1 \dagger$ & $10.8^{*}$ & $3.11^{*}$ \\
\hline s.d. & 16.25 & 0.5 & 38.4 & 3.5 & 7.4 & 3.61 \\
\hline \multicolumn{7}{|l|}{ Control } \\
\hline & 0.49 & 0.5 & 1.53 & 2.67 & - & - \\
\hline 443 & 1.08 & 1 & 3.54 & 1.88 & 4 & 0.58 \\
\hline 444 & 2.29 & 1 & 10.6 & 3.40 & 6 & 1.03 \\
\hline 434 & 0.49 & 0.5 & 1.25 & 4.29 & - & - \\
\hline 436 & 0.60 & 0.5 & 1.45 & 1.69 & 3 & 0.26 \\
\hline 441 & 0.66 & 0.6 & 2.49 & 1.31 & 2 & 0.52 \\
\hline 440 & 0.97 & 0.6 & 1.91 & 2.37 & - & - \\
\hline 435 & 0.94 & 0.5 & 1.93 & 6.60 & 4 & 0.21 \\
\hline 442 & 0.91 & 0.5 & 2.98 & 3.43 & 3.1 & 0.44 \\
\hline 454 & 3.07 & 1 & 8.26 & 2.61 & - & - \\
\hline 448 & 1.18 & 1 & 3.56 & 4.75 & 8 & 0.26 \\
\hline 453 & 1.07 & 0.5 & 2.96 & 3.42 & - & - \\
\hline Mean & 1.15 & 0.68 & 3.54 & 3.20 & 4.3 & 0.47 \\
\hline s.d. & 0.77 & 0.24 & 2.40 & 1.48 & 2.1 & 0.28 \\
\hline
\end{tabular}

$* P<0.05, t$-test $v s$ controls.

$\dagger P=0.05 t$-test $v s$ controls. 
The maximum plasma drug concentration was about 16 times higher in cirrhotics than in controls $(P<0.01)$ but occurred at the same time after drug administration in both groups $(P=0.56)$. The buspirone elimination half-life in cirrhotics was about twice that of the normal subjects $(P=$ 0.05). Eight of the cirrhotics and seven of the controls had two peaks in the plasma drug concentration-time curve. The second peak appeared between 4 and $24 \mathrm{~h}$ after drug administration in the cirrhotics and between 2 and $8 \mathrm{~h}$ after drug administration in the controls. Concentrations of the second peak ranged from $0.10 \mathrm{ng} \mathrm{ml}^{-1}$ to $9.58 \mathrm{ng} \mathrm{ml}^{-1}$ in the cirrhotics and from $0.21 \mathrm{ng}$ $\mathrm{ml}^{-1}$ to $1.03 \mathrm{ng} \mathrm{ml}^{-1}$ in the controls.

No significant or systematic changes were seen in the liver blood tests, or ECG during the trial. There was no significant correlation between buspirone AUC and liver blood tests, antipyrine clearance and galactose elimination.

\section{Side effects}

Eight of the 24 study participants (three subjects and five patients) reported adverse effects within 20-45 min after dosing. One control subject reported nausea and lack of concentration. The remaining seven subjects experienced one or more episodes of sedation, or both. All events were mild and disappeared within $0.5-4 \mathrm{~h}$ after onset, without any treatment.

\section{Discussion}

The primary results of this study were that, after a single oral dose of buspirone, both plasma drug concentrations and AUC were approximately 16 times higher in patients with cirrhosis than in healthy subjects.

\section{References}

Blaschke, T. F. (1977). Protein binding and kinetics of drugs in liver disease. Clin. Pharmacokin., 2, 32-44.

Døssing, M., Poulsen, H. E., Andreasen, P. B. \& Tygstrup, N. (1982). A simple method for determination of antipyrine clearance. Clin. Pharmac. Ther., 32, 392-396.

Garattini, S., Caccia, S. \& Mennini, T. (1982). Notes on buspirone's mechanisms of action. J. clin. Psychiat., 43, 19-22.

Mayol, R. F., Marvel, C. J. La Budde, J. A. (1981). Development and validation of a radioimmunoassay for buspirone. Fed. Proc., 40, 684.

Mayol, R. F., Adamson, D. S., Gammans, R. E. \& La Budde, J. A. (1985). Pharmacokinetics and disposition of $\mathrm{C}-14$ buspirone $\mathrm{HCl}$ after intravenous
The results of an oral tracer study in normal subjects (Mayol et al., 1985) indicated complete gastrointestinal absorption, but only $1-10 \%$ of the dose reached the systemic circulation unmetabolized. It seems unlikely that the differences in AUC values are due to changes in absorptive capacity between normal subjects and patients with cirrhosis. A high degree of hepatic shunting and moderate decreased hepatic elimination is the most likely explanation of the 16-fold elevated buspirone peak concentration and the moderately decreased elimination halflife in patients with cirrhosis.

The large first pass effect implies that the normal liver has a high intrinsic buspirone metabolism capacity and that the extraction ratio is greater than 0.7 . This would place buspirone in the flow-limited hepatic clearance class (Blaschke, 1977). Therefore, reduction in hepatic blood flow in patients with hepatic cirrhosis should contribute to the decreased elimination rate.

The secondary plasma drug peaks indicate some biliary excretion of intact buspirone, but excretion apparently is not influenced by the severity of the cirrhosis as evaluated by antipyrine clearance and galactose elimination. The absence of differences between patients and controls in secondary peaks would seem to exclude cholestasis as a factor in the changes in apparent buspirone clearance.

Buspirone AUC could not be correlated with liver function markers such as serum albumin levels, antipyrine clearance or galactose elimination rate, indicating a different effect of cirrhosis on the synthesis or metabolism of these substances.

On the kinetic evidence from this study buspirone should be used with caution in liver disease.

and oral dosing in man. Clin. Pharmac. Ther., 37, 210.

Riblet, L. A., Taylor, D. P., Eison, M. S. \& Stanton, H. C. (1982). Pharmacology and neurochemistry of buspirone. J. clin. Psychiat., 43, 11-16.

Temple, D. L., Yevich, J. P. \& New, J. S. (1982). Buspirone: Chemical profile of a new class of anxioselective agents. J. clin. Psychiat., 43, 4-9.

Tygstrup, N. (1966). Determination of the hepatic elimination capacity $(\mathrm{Lm})$ of galactose by single injection. Scand. J. clin. Lab. Invest., 18 (suppl. 92), 118-125.

(Received 21 October 1986, accepted 10 June 1987) 